
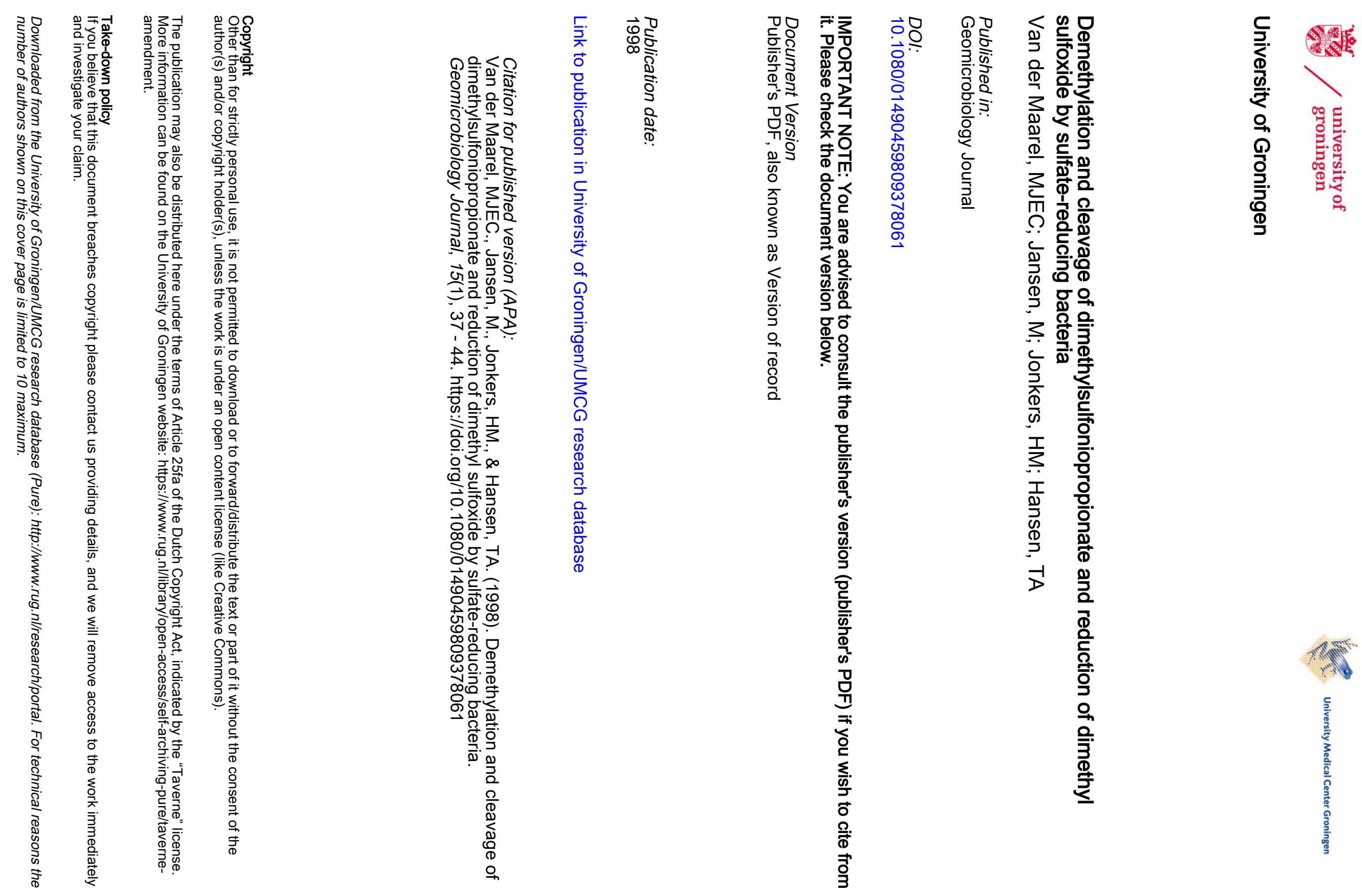

동

के ซ유

당으

3 유을

등

일

$\frac{\hat{0}}{\omega} \stackrel{0}{\omega}$

곤 흥

등ㅇㅁㅇ

要

\

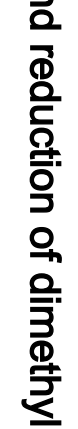

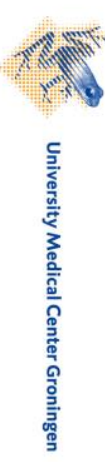




\title{
Demethylation and Cleavage of Dimethylsulfoniopropionate and Reduction of Dimethyl Sulfoxide by Sulfate-Reducing Bacteria
}

\author{
MARC J. E. C. VAN DER MAAREL \\ MICHAEL JANSEN \\ HENK M. JONKERS \\ THEO A. HANSEN
}

Department of Microbiology

University of Groningen

Haren, The Netherlands

\begin{abstract}
Many marine algae contain high concentrations of dimethylsulfoniopropionate (DMSP); most likely this compound functions mainly as an osmolyte. In anoxic marine sediments DMSP can be degraded in two ways: via an initial demethylation, or via a cleavage to dimethyl sulfide (DMS) and acrylate. Although the occurrence of these processes in sediments was known, the types of organisms responsible for them were not. Recent data from our laboratory, however, have shown that certain types of sulfate-reducing bacteria can carry out a demethylation of DMSP, whereas another sulfate reducer was found to cleave DMSP to DMS and acrylate, which was reduced to propionate. Thus, sulfate-reducing bacteria might be responsible for at least a part of the observed DMSP transformations in anoxic sediments. It was also shown that a well-known oxidation product of DMS, dimethyl sulfoxide, can function as an alternative electron acceptor in the metabolism of some marine sulfate reducers. These data are reviewed in the present article.
\end{abstract}

Keywords acrylate reduction, Desulfobacterium, Desulfovibrio, dimethyl sulfoxide reduction, dimethylsulfoniopropionate cleavage, dimethylsulfoniopropionate demethylation

Dimethylsulfoniopropionate (DMSP) is thought to play a key role in the global sulfur cycle. This compound, which is present in rather high concentrations in many marine macro- and microalgae and in a few higher plants, supposedly has a major function as an osmolyte (Kirst 1996) and may function as a cryoprotectant in certain cases (Karsten et al. 1996). It is easily cleaved to yield dimethyl sulfide (DMS) and acrylate, either chemically at high pH (Dacey and Blough 1987) or biochemically at normal pH values by the enzyme dimethylsulfoniopropionate lyase from algae or bacteria. A second degradation pathway proceeds via an initial demethylation by bacteria to methylthiopropionate (MTPA). A small part of the DMS produced in the marine environment escapes to the atmosphere. There, DMS is oxidized to methanesulfonic acid and sulfuric acid, compounds that are thought to act as cloud-condensation nuclei, and to dimethyl sulfoxide and $\mathrm{SO}_{2}$

Received June 18, 1997; accepted July 10, 1997.

The authors were supported by grants from the National Research Programme of the Netherlands government (project NOLK/026/90), the Netherlands Organization for Scientific Research, the European Union (EV5V-CT93-036), and Quest International b.v.

Address correspondence to Theo A. Hansen, Department of Microbiology, University of Groningen, Kerklaan 30, NL-9751 NN Haren, The Netherlands. E-mail: hansenta@biol.nug.nl. 
(Charlson 1993). Sulfur from the marine environment can be transported to the land in the form of DMS itself and its oxidation products. Aerobically, DMSP, DMS, and some of its incomplete oxidation products have been shown to be oxidized by a variety of bacteria. Both DMSP-cleaving bacteria (Ledyard et al. 1993; de Souza and Yoch 1995) and DMSP-demethylating aerobic marine bacteria (Taylor and Gilchrist 1991) have been studied and several marine DMS-oxidizing bacteria (Taylor and Visscher 1996; de Zwart et al. 1996) and methanesulfonic-acid oxidizing bacteria (Thompson et al. 1995) have been isolated.

Cleavage and demethylation of DMSP also occur in anoxic parts of salt marshes and marine sediments, and the products DMS and 3-mercaptopropionate have been detected (Kiene and Taylor 1988b). Facultatively anaerobic denitrifying DMS-oxidizing bacteria have been isolated from a microbial mat on a salt-marsh sediment (Visscher and Taylor 1993), and DMS has been shown to be a substrate for methanogenic archaea (Finster et al. 1992; Oremland and Boone 1994), but until recently little was known about the types of anaerobic prokaryotes involved in DMSP cleavage and demethylation. Here, we review recent data that show that sulfate-reducing bacteria can be involved in various ways in the anaerobic metabolism of DMSP and related compounds.

\section{Demethylation of DMSP}

The demethylation of DMSP in oxic as well as in anoxic marine sediments results in the production of either 3-mercaptopropionate (MPA) or methanethiol, with MTPA as an intermediate (Kiene and Taylor 1988a, 1988b; Taylor and Gilchrist 1991). A striking difference, however, is that under oxic conditions the production of MTPA from DMSP and the further conversion to MPA (Visscher and Taylor 1994) or the metabolism via a yet unknown pathway yielding methanethiol (Diaz and Taylor 1996; Taylor and Gilchrist 1991) can be performed by the same organism, while under anoxic conditions DMSP demethylation to MTPA and its further conversion seem to be due to the activity of different microorganisms (van der Maarel et al. 1993, 1995). Kiene and Taylor (1988a) showed that the rate of formation of MPA from MTPA in anoxic sediment slurries is similar to the formation rate of MPA when DMSP was added to the slurry. They concluded that MTPA has to be an intermediate in the demethylation pathway, but did not measure its possible formation during the slurry experiments. With the description of the first anaerobic bacterium that demethylates DMSP to MTPA, it was shown that MTPA can indeed be an intermediate in the demethylation pathway (van der Maarel et al. 1993). This strain, which was identified as a Desulfobacterium niacini (van der Maarel et al. 1996b), was isolated with the DMSP-analog glycine betaine as a substrate (Heijthuijsen and Hansen, 1989). Recently, the demethylation of DMSP to MTPA by two other Desulfobacterium strains has been described (van der Maarel et al. 1996b).

To test whether new types of DMSP-demethylating bacteria can be isolated from anoxic intertidal sediment with DMSP as a substrate we set up enrichment cultures in mineral medium containing sulfate as potential electron acceptor. The inoculum was diluted up to a factor $10^{5}$ to avoid rapid DMSP cleavage by free DMSP lyase from the sediment or by DMSP-cleaving bacteria. This enrichment strategy resulted in the isolation of a DMSP-demethylating, sulfate-reducing bacterium (strain WN) that is physiologically and morphologically similar to the previously described DMSP-demethylating Desulfobacterium strain (van der Maarel et al. 1993). However, a phylogenetic analysis on the basis of the 16S rRNA gene sequence showed that the newly isolated bacterium is more related to the genera Desulfobacula and Desulfobacter, which do not demethylate DMSP. 
For two of the DMSP-demethylating strains, strain PM4 and WN, the apparent $K_{m}$ for DMSP was determined to be 9 and $10 \mu \mathrm{M}$, respectively (van der Maarel et al. 1996b). These values are of the same order of magnitude as the concentrations of DMSP that have been measured in the sediment from which strain WN originates (van der Maarel et al. 1993). The low apparent $K_{m}$ value for DMSP of strains WN and PM4 and the high dilution from which strain WN could be isolated indicate that such organisms could be important members of the DMSP-demethylating microbial community.

The biochemical mechanism of DMSP demethylation in sulfate-reducing bacteria is currently under study. Van der Maarel et al. (1996a) already showed that enzymes of the oxidative acetyl coenzyme $\mathrm{A}(\mathrm{CoA}) / \mathrm{CO}$ dehydrogenase pathway are present in strain WN. In the oxidative acetyl $\mathrm{CoA} / \mathrm{CO}$ dehydrogenase pathway the methyl group of acetate is oxidized to $\mathrm{CO}_{2}$ via a methyltetrahydropterin and other $\mathrm{C}_{1}$-tetrahydropterins (Widdel and Hansen 1992). Most likely, one of the methyl groups of DMSP can be transferred directly to the tetrahydropterin by a methyltransferase or indirectly via a corrinoid protein. Preliminary experiments with cell extracts of DMSP-grown cells of strain WN have shown the presence of a DMSP methyltransferase that can use tetrahydrofolic acid as acceptor (Jansen, unpublished results).

\section{Cleavage of DMSP}

The cleavage of DMSP to DMS, acrylate, and a proton has been described for the plant species Wollastonia biflora (James et al. 1995), several algae (Cantoni and Anderson 1956; Stefels and van Boekel 1993; Nishiguchi and Goff 1995; de Souza and Yoch 1996a), and a variety of aerobic bacteria (Kiene 1990; Taylor and Gilchrist 1991; Diaz et al. 1992; Ledyard et al. 1993; de Souza and Yoch 1995; Diaz and Taylor 1996). DMSP can undergo cleavage to DMS and acrylate in anoxic intertidal sediment; this process is neither inhibited by 2-bromoethanesulfonate, a specific inhibitor of methanogenesis, nor by molybdate, an inhibitor of sulfate reduction (Kiene and Visscher 1987). Addition of glutaraldehyde or autoclaving of the sediment, however, resulted in an almost complete inhibition of DMS formation from DMSP. Based on these results the authors showed that the cleavage of DMSP is a biological process, but were not able to show the involvement of a particular group of microorganisms. They suggested that fermentative bacteria such as clostridia, which are not affected by the inhibitors applied in the slurry experiments, might have been responsible for the breakdown of DMSP. This suggestion was based on the description of DMSP cleavage and subsequent acrylate fermentation by a freshwater strain of Clostridium propionicum; until recently, this was the only known DMSP-cleaving anaerobe (Wagner and Stadtman 1962). Similar results concerning the inhibition of DMSP cleavage were obtained by Visscher and van Gemerden (1991) for marine microbial mat slurries. They also showed that DMSP was more rapidly consumed under anoxic than under oxic conditions, which has also been found in experiments using diatom mat slurries (Visscher et al. 1994). Besides biological formation, a high $\mathrm{pH}$ tends to stimulate the abiotic formation of DMS from DMSP (Dacey and Blough 1987). In the ocean high $\mathrm{pH}$ values are very unlikely, but increasing $\mathrm{pH}$ values up to $\mathrm{pH} 10.5$ have been observed in microbial mats due to bicarbonate consumption at times of active photosynthesis (Visscher and van Gemerden 1991).

In most of the studies on the cleavage of DMSP in anoxic marine sediments only DMS was quantified as a cleavage product. Kiene and Taylor (1988a) showed that acrylate accumulated in sediment slurries after the addition of relatively high concentrations of DMSP $(700 \mu \mathrm{M})$. Acrylate can subsequently be converted by the organism that is also 
responsible for the cleavage of DMSP, such as Clostridium propionicum (Wagner and Stadtman 1962), or by others that do not have a DMSP-cleaving enzyme (Janssen 1991; de Souza and Yoch 1996b). Because no anaerobic marine DMSP-cleaving bacteria had been described in the literature, we set up an enrichment culture in bicarbonate-buffered mineral medium containing DMSP and yeast extract but no sulfate. Sediment from the Wadden Sea near Westernieland, the Netherlands, was used as an inoculum. After a few transfers into fresh medium, DMSP was cleaved rapidly and propionate was formed after a transient accumulation of acrylate. From this enrichment culture a pure culture of a DMSP-cleaving bacterium (strain W218) was isolated (van der Maarel et al. 1996c). After cleavage of DMSP, strain W218 produced only propionate from the accumulated acrylate. This result was unexpected, as it was anticipated that fermentation of acrylate resulting in the formation of acetate and propionate in a 1:2 ratio, similar to what had been described for Clostridium propionicum (Wagner and Stadtman 1962; Janssen 1991), would occur. It turned out that strain W218 did not ferment the acrylate, but used it as an electron acceptor for the incomplete oxidation of the electron donor(s) such as lactate or amino acids from the yeast extract. Besides acrylate it can also use sulfate and thiosulfate as alternative electron acceptors. On the basis of its physiological characteristics and its 16S rRNA gene sequence, strain W218 was assigned to the genus Desulfovibrio as the new species Desulfovibrio acrylicus (van der Maarel et al. 1996c). The apparent $K_{\mathrm{m}}$ value for DMSP, as determined from the DMS production rate of whole cells, was approximately $0.4 \mathrm{mM}$.

A very active DMSP-cleaving enzyme was purified from Desulfovibrio acrylicus strain W218 (van der Maarel et al. 1996a). The enzyme had a $K_{\mathrm{m}}$ for DMSP of $0.45 \mathrm{mM}$ and a $V_{\max }$ of approximately $2.6 \mathrm{mmol}$ acrylate formed/min॰mg protein; it was only active toward DMSP and was strongly inhibited by dimethylsulfoniobutyrate, with a $K_{i}$ of 0.25 $\mathrm{mM}$. The purified DMSP lyase from strain W218 was not completely inhibited by $0.5 \%$ glutaraldehyde, a compound commonly used to preserve sediment samples for later analysis of DMSP and its metabolic products. This result implies that for determination of the actual in situ DMSP concentration, more glutaraldehyde, for example, $1.0 \%$ or a combination of $0.5 \%$ glutaraldehyde and acidification of the sediment sample to a $\mathrm{pH}$ of 4 , has to be used (Jonkers, unpublished results). It also indicates that the concentrations of DMSP that have been reported in the literature might be underestimates of the actual value (e.g., Visscher et al. 1991).

The high apparent $K_{\mathrm{m}}$ values for DMSP of whole cells of strain W218 (400 $\left.\mu \mathrm{M}\right)$ and the low values of the demethylating strains WN and PM4 (approximately $10 \mu \mathrm{M}$ ) indicate that at higher DMSP concentrations the share of the cleavage pathway in sediments will increase. This is in agreement with the results of Kiene and Taylor (1988a) on the relative importance of the DMSP conversion pathways in sediment slurries.

\section{Dimethyl Sulfoxide Reduction by Sulfate-Reducing Bacteria}

Dimethyl sulfoxide (DMSO) is a potential alternative electron acceptor for certain microorganisms, which is not surprising in view of the suitable midpoint potential of DMSO/DMS ( $+160 \mathrm{mV})$; it has been shown to be reduced in anaerobic cultures of a wide variety of bacteria including Escherichia coli and strains of Pseudomonas, Rhodobacter, Wolinella, and of halophilic archaea (e.g., Weiner et al. 1992; Lorenzen et al. 1994). Until recently, there were no indications that sulfate-reducing bacteria can use DMSO as an alternative electron acceptor. Zinder and Brock (1978) showed that a freshwater isolate of Desulfovibrio did not reduce DMSO to DMS. Furthermore, in studies with anoxic salt- 
marsh sediments Kiene and Capone (1988) found that reduction of DMSO added to such sediments was not inhibited by $20 \mathrm{mM}$ molybdate, a known inhibitor of sulfate reduction.

We reinvestigated DMSO reduction by sulfate reducers using a variety of pure cultures from different habitats (Jonkers et al. 1996). Cultures of the marine strains Desulfobacterium niacini DSM 2650, Desulfovibrio desulfuricans PA2805, Desulfovibrio vulgaris DSM 1744, Desulfovibrio sp. DSM 3099, and Desulfovibrio halophilus DSM 5663, which originates from a hypersaline environment, could be grown in media without sulfate but with DMSO as electron acceptor. Four other marine strains, one strain from a brackish environment, and three freshwater strains did not grow under these conditions. The growth with DMSO of Desulfovibrio desulfuricans PA2805 was studied in more detail. DMSO reduction and sulfate reduction proceeded simultaneously if both electron acceptors were present. The specific growth rates with sulfate or DMSO as electron acceptor and lactate as energy source were approximately the same, but the molar growth (on lactate) was slightly higher with DMSO than with sulfate. It is not known where the DMSO reductase activity of this strain is located. In Escherichia coli the enzyme is associated with the inner aspect of the cytoplasmic membrane (Weiner et al. 1992), whereas the enzyme is periplasmic in Rhodobacter sphaeroides (Hilton and Rajagopalan 1996).

If both $5 \mathrm{mM}$ DMSO and $20 \mathrm{mM}$ molybdate were added to a culture of Desulfovibrio desulfuricans PA2805 growing with lactate and sulfate, growth came to a halt but DMSO was reduced to DMS (Jonkers et al. 1996). At first sight, these data are in conflict with the findings of Kiene and Capone (1988) in sediment experiments. However, a major difference from their experiments is the time scale. They studied the production of DMS from DMSO added to sediments for several days, whereas we looked at the effects of molybdate over a period of $5 \mathrm{~h}$. Addition of molybdate to sulfate-reducing cultures is known to lead to a rapid drain of the ATP pool and thus will affect sulfate reduction and growth because sulfate can no longer be activated to APS (Oremland and Capone 1988). In the case of DMSO reduction, activation of the electron acceptor plays no role; therefore, it is not unexpected that molybdate does not block DMSO reduction but that growth does stop (as a result of ATP depletion). Our data show that sulfate-reducing bacteria may play a role in DMSO reduction in sediments. However, we have no data about their behaviour at in situ DMSO concentrations. Interestingly, a strain of the recently described barophilic sulfate-reducing bacterium Desulfovibrio profundus was also found to reduce dimethyl sulfoxide (Bale et al. 1997).

\section{Concluding Remarks}

Sulfate-reducing bacteria can be involved in anaerobic DMSP metabolism in different ways (see Figure 1): DMSP cleavage, DMSP demethylation, and DMSO reduction. There is another related process where sulfate reducers might play a major role, namely, the oxidation of DMS to $\mathrm{CO}_{2}$. Kiene et al. (1986) found that ${ }^{14} \mathrm{C}$-DMS when added to anoxic sediments at approximately $2 \mu \mathrm{M}$ was mainly converted to ${ }^{14} \mathrm{CO}_{2}$. At millimolar levels, however, DMS was a methanogenic substrate. The conversion of micromolar concentrations of DMS to $\mathrm{CO}_{2}$ was strongly inhibited by molybdate; 2-bromoethane sulfonic acid did not block the $\mathrm{CO}_{2}$ production. These data suggest that at the low in situ concentrations DMS is mainly oxidized by sulfate-reducing bacteria. There is only one report on DMS oxidation by a pure culture of sulfate reducers; this thermophilic strain was isolated from a sludge fermentor (Tanimoto and Bak 1994). Thus far, attempts at isolating mesophilic DMS oxidizing sulfate-reducing bacteria from marine and estuarine sediments in our laboratory have been unsuccessful. 


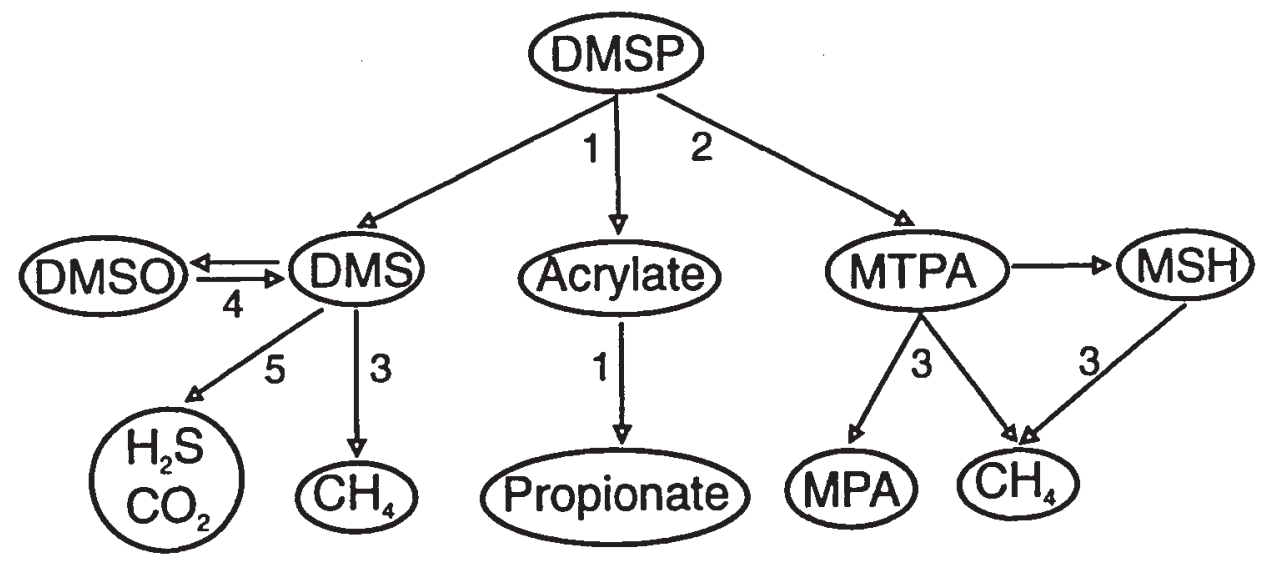

Figure 1. Conversion of dimethylsulfoniopropionate in anoxic marine sediments and the role of sulfate-reducing bacteria and methanogenic archaea. Abbreviations: DMSP, dimethylsulfoniopropionate; DMS, dimethyl sulfide; DMSO, dimethyl sulfoxide; MPA, 3-mercaptopropionate; MTPA, 3methylthiopropionate; MSH, methanethiol. Numbers indicate the following organisms: 1, Desulfovibrio acrylicus (van der Maarel et al., 1996c); 2, some Desulfobacterium species and strain WN (van der Maarel et al., 1996b); 3, certain methanogenic archaea (van der Maarel et al., 1995); 4, certain marine Desulfovibrio species and Desulfobacterium niacini (Jonkers et al., 1996); 5, unknown sulfate-reducing bacteria (Kiene et al., 1986).

\section{References}

Bale SJ, Goodman K, Rochelle PA, Marchesi JR, Fry JC, Weightman AJ, Parkes RJ. 1997. Desulfovibrio profundus sp. nov., a novel barophilic sulfate-reducing bacterium from deep sediment layers in the Japan Sea. Int J Syst Bacteriol 47:515-521.

Cantoni GL, Anderson DG. 1956. Enzymatic cleavage of dimethylsulfoniopropiothetin by Polysiphonia lanosa. J Biol Chem 222:171-177.

Charlson RJ. 1993. Gas-to-particle conversion and CCN production. In: Restelli G, Angeletti G, editors. Dimethylsulphide: oceans, atmosphere and climate. Dordrecht: Kluwer, p 275-86.

Dacey JWH, Blough NV. 1987. Hydroxide decomposition of dimethylsulfoniopropionate to dimethylsulfide. Geophys Res Lett 14:1246-9.

de Souza MP, Yoch DC. 1995. Comparative physiology and dimethyl sulfide production by dimethylsulfoniopropionate lyase in Pseudomonas doudoroffii and Alcaligenes sp. strain M3A. Appl Environ Microbiol 61:3986-91.

de Souza MP, Chen YP, Yoch DC. 1996a. Dimethylsulfoniopropionate lyase from the marine macroalga Ulva curvata: purification and characterization of the enzyme. Planta 199:433-8.

de Souza MP, Yoch DC. 1996b. Differential metabolism of dimethylsulfoniopropionate and acrylate in saline and brackish intertidal sediments. Microb Ecol 31:319-30.

de Zwart JMM, Nelisse PN, Kuenen JG. 1996. Isolation and characterization of Methylophaga sulfidovorans sp. nov.: an obligately methylotrophic, aerobic, dimethylsulfide oxidizing bacterium from a microbial mat. FEMS Microbiol Ecol 20:261-70.

Diaz MR, Taylor BF. 1996. Metabolism of methylated osmolytes by aerobic bacteria from Mono Lake, a moderately hypersaline, alkaline environment. FEMS Microbiol Lett 19:239-47.

Diaz MR, Visscher PT, Taylor BF, 1992. Metabolism of dimethylsulfoniopropionate and glycine betaine by a marine bacterium. FEMS Microbiol Lett 96:61-6.

Finster K, Tanimoto Y, Bak F. 1992. Fermentation of methanethiol and dimethylsulfide by a newly isolated methanogenic bacterium. Arch Microbiol 157:425-30.

Heijthuijsen JHFG, Hansen TA. 1989. Anaerobic degradation of betaine by marine Desulfobacterium strains. Arch Microbiol 152:393-6. 
Hilton JC, Rajagopalan KV. 1996. Molecular cloning of dimethylsulfoxide reductase from Rhodobacter sphaeroides. Biochim Biophys Acta 1294:111-4.

James F, Paquet L, Sparace SA, Gage DA, Hanson AD. 1995. Evidence implicating dimethylsulfoniopropionaldehyde as an intermediate in dimethylsulfoniopropionate biosynthesis. Plant Physiol 108:1439-48.

Janssen PH. 1991. Isolation of Clostridium propionicum strain 19acry3 and further characteristics of the species. Arch Microbiol 155:566-71.

Jonkers HM, van der Maarel MJEC, van Gemerden H, Hansen TA. 1996. Dimethylsulfoxide reduction by sulfate-reducing bacteria. FEMS Microbiol Lett 136:283-7.

Karsten U, Kück K, Vogt C, Kirst GO. 1996. Dimethylsulfoniopropionate production in phototrophic organisms and its physiological function as a cryoprotectant. In: Kiene RP, Visscher PT, Keller MD, Kirst GO, editors. Biological and environmental chemistry of DMSP and related compounds. New York: Plenum Press. p 143-54.

Kiene RP. 1990. Dimethyl sulfide production from dimethylsulfoniopropionate in coastal seawater samples and bacterial cultures. Appl Environ Microbiol 56:3292-7.

Kiene RP, Capone DG. 1988. Microbial transformation of methylated sulfur compounds in anoxic salt marsh sediments. Microb Ecol 15:275-91.

Kiene RP, Oremland RS, Catena A, Miller LG, Capone DG. 1986. Metabolism of reduced methylated sulfur compounds in anaerobic sediments and by a pure culture of an estuarine methanogen. Appl Environ Microbiol 52:1037-45.

Kiene RP, Taylor BF. 1988a. Demethylation of dimethylsulfoniopropionate and production of thiols in anoxic marine sediments. Appl Environ Microbiol 54:2208-12.

Kiene RP, Taylor BF. 1988b. Biotransformations of organosulphur compounds in sediments via 3mercaptopropionate. Nature 332:148-50.

Kiene RP, Visscher PT. 1987. Production and fate of methylated sulfur compounds from methionine and dimethylsulfoniopropionate in anoxic salt marsh sediments. Appl Environ Microbiol 53:2426-34.

Kirst GO. 1996. Osmotic adjustment in phytoplankton and macroalgae. In: Kiene RP, Visscher PT, Keller MD, Kirst GO, editors. Biological and environmental chemistry of DMSP and related compounds. New York: Plenum Press. p 121-30.

Ledyard KM, De Long EF, Dacey JWH. 1993. Characterization of a DMSP-degrading bacterial isolate from the Sargasso Sea. Arch Microbiol 160:312-8.

Lorenzen J, Steinwachs S, Unden G. 1994. DMSO respiration by the anaerobic rumen bacterium Wolinella succinogenes. Arch Microbiol 162:277-81.

Nishiguchi MK, Goff LJ. 1995. Isolation, purification, and characterization of DMSP lyase (dimethylpropiothetin dethiomethylase (4.4.1.3)) from the red alga Polysiphonia paniculata. J Phycol 31:567-74.

Oremland RS, Boone DR. 1994. Methanolobus taylorii sp. nov., a new methylotrophic estuarine methanogen. Int J Syst Bacteriol 41:410-6.

Oremland RS, Capone DG. 1988. Use of "specific inhibitors" in biogeochemistry and microbial ecology. Adv Microb Ecol 10:285-383.

Stefels J, van Boekel WHM. 1993. Production of DMS from dissolved DMSP in axenic cultures of the marine phytoplankton species Phaeocystis sp. Mar Ecol Prog Ser 97:11-8.

Tanimoto T, Bak F. 1994. Anaerobic degradation of methylmercaptan and dimethyl sulfide by newly isolated thermophilic sulfate-reducing bacteria. Appl Environ Microbiol 60:2450-5.

Taylor BF, Gilchrist DC. 1991. New routes for aerobic biodegradation of dimethylsulfoniopropionate. Appl Environ Microbiol 57:3581-4.

Taylor BF, Visscher PT. 1996. Metabolic pathways involved in DMSP degradation. In: Kiene RP, Visscher PT, Keller MD, Kirst GO, editors. Biological and environmental chemistry of DMSP and related compounds. New York: Plenum Press. p 265-76.

Thompson AS, Owens NJP, Murrell JC. 1995. Isolation and characterization of methanesulfonic aciddegrading bacteria from the marine environment. Appl Environ Microbiol 61:2388-93. 
van der Maarel MJEC, Aukema W, Hansen TA. 1996a. Purification and characterization of a dimethylsulfoniopropionate cleaving enzyme from Desulfovibrio acrylicus. FEMS Microbiol Lett 143:241-5.

van der Maarel MJEC, Jansen M, Haanstra R, Meijer WG, Hansen TA. 1996b. Demethylation of dimethylsulfoniopropionate to 3-S-methylmercaptopropionate by marine sulfate-reducing bacteria. Appl Environ Microbiol 62:3978-84.

van der Maarel MJEC, Jansen M, Hansen TA. 1995. Methanogenic conversion of 3-S-methylmercaptopropionate to 3-mercaptopropionate. Appl Environ Microbiol 61:48-51.

van der Maarel MJEC, Quist P, Dijkhuizen L, Hansen TA. 1993. Degradation of dimethylsulfoniopropionate to 3-S-methylmercaptopropionate by a marine Desulfobacterium strain. Arch Microbiol 60:411-2.

van der Maarel MJEC, van Werkhoven AF, Laverman AM, Meijer WG, Stam WT, Hansen TA. 1996c. Cleavage of dimethylsulfoniopropionate and reduction of acrylate by Desulfovibrio acrylicus sp. nov. Arch Microbiol 166:109-15.

Visscher PT, Quist P, van Gemerden H. 1991. Methylated sulfur compounds in microbial mats: in situ concentrations and metabolism by a colorless sulfur bacterium. Appl Environ Microbiol 57:1758-63.

Visscher PT, Kiene RP, Taylor BF. 1994. Demethylation and cleavage of dimethylsulfoniopropionate in marine intertidal sediments. FEMS Microbiol Ecol 14:179-90.

Visscher PT, Taylor BF. 1993. Aerobic and anaerobic degradation of a range of alkyl sulfides by a denitrifying marine bacterium. Appl Environ Microbiol 59:4083-9.

Visscher PT, van Gemerden H. 1991. Production and consumption of dimethylsulfoniopropionate in marine microbial mats. Appl Environ Microbiol 57:3237-42.

Wagner C, Stadtman ER. 1962. Bacterial fermentation of dimethyl- $\beta$-propiothetin. Arch Biochem Biophys 57:3237-42.

Weiner JH, Rothery RA, Sambasivarao D, Trieber CA. 1992. Molecular analysis of dimethylsulfoxide reductase: a complex iron-sulfur molybdoenzyme of Escherichia coli. Biochim Biophys Acta 1102:1-18.

Widdel F, Hansen TA. 1992. The dissimilatory sulfate- and sulfur-reducing bacteria. In: Balows A, Trüper HG, Dworkin M, Harder W, Schleifer K-H, editors. The prokaryotes. 2nd ed. New York: Springer-Verlag. p 583-624.

Zinder S, Brock TD. 1978. Dimethyl sulfoxide as an electron acceptor for anaerobic growth. Arch Microbiol. 116:35-40. 